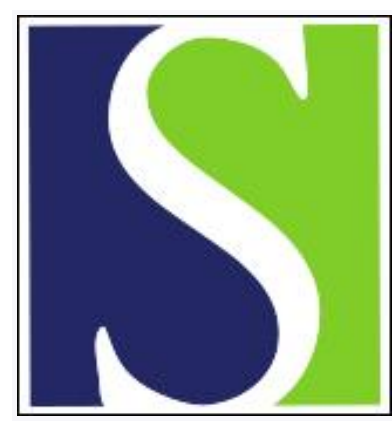

Scand J Work Environ Health 1996;22(2):150-153

https://doi.org/10.5271/sjweh.124

Issue date: Apr 1996

Elevated urinary cadmium concentrations in a patient with acute cadmium pneumonitis

by Ando Y, Shibata E, Tsuchiyama F, Sakai S

Key terms: case report; complication; diagnosis; metal fume

This article in PubMed: www.ncbi.nlm.nih.gov/pubmed/8738895 


\title{
Elevated urinary cadmium concentrations in a patient with acute cadmium pneumonitis
}

\author{
by Yuichi Ando, MD, 1,4 Eiji Shibata, MD, ${ }^{2}$ Fumi Tsuchiyama, ${ }^{3}$ Shuzo Sakai, $M D^{4}$
}

\begin{abstract}
Ando $Y$, Shibata E, Tsuchiyama F, Sakaj S. Elevated urinary cadmium concentrations in a patient with acute cadmium pneumonitis. Scand J Work Environ Health 1996;22:150-3.

Background Acute serious inhalation of cadmium fumes often causes chemical pneumonitis or metal fume fever. Because symptoms of both diseases begin several hours after exposure and closely mimic each other, one often mistakes chemical pneumonitis for metal fume fever in the early stages. It is, however, essential to differentiate between the two since chemical pneumonitis can progress to serious consequences.

Case A 43-year-old man was admitted to the hospital $2 \mathrm{~d}$ after exposure to cadmium fumes. The initial diagnosis was metal fume fever on the basis of his history, and he was treated accordingly. His symptoms worsened however, and transient renal impairment was identified as consistent with cadmium-induced renal toxicity. Although the possibility of drug-induced renal damage could not be excluded, abnormal urinalysis findings on admission suggested that the renal tubular damage was caused by inhaled cadmium before admission.

Conclusions Measuring the urinary cadmium concentration is an effective method for confirming acute cadmium poisoning.
\end{abstract}

Key terms case report, complication, diagnosis, metal fume.

Silver soldering easily generates cadmium fumes since the melting and boiling points of cadmium contained within an alloy are lower than those of other metals within the same alloy (1). Hara et al reported that silver solder fumes contained a very high percentage of cadmium (about $85 \%$ ) in a typical soldering procedure, while that of the original alloy was about $24 \%$ (1). Acute serious inhalation of cadmium fumes often causes chemical pneumonitis or metal fume fever $(2,3)$. Because symptoms of both diseases begin several hours after exposure and they closely mimic each other, one often mistakes chemical pneumonitis for metal fume fever in the early stages (4). However, chemical pneumonitis may progress to serious consequences such as pulmonary edema and fatal respiratory failure. Therefore, it is essential that chemical pneumonitis be included in the differential diagnosis of any patients presenting symptoms of metal fume fever (4). If the presence of excessive exposure to cadmium is unclear, a finding of excessive urinary cadmium may help to confirm the diagnosis (3). Although episodes of high exposure to cadmium may lead to a transient increased urinary excretion of this metal (5), there are few data measuring serial urinary cadmium concentrations after such episodes. We present a patient with cadmium pneumonitis in whom consecutive urinary cadmium concentrations were measured after the exposure.

\section{Case report}

A 43-year-old man was admitted to our hospital because of severe dyspnea. Two days prior to admission, he had repaired a large iron pot $50 \mathrm{~cm}$ in diameter and $20 \mathrm{~cm}$ in depth) by soldering to it with a silver alloy containing cadmium. He painstakingly filled in the dents at the bottom of the pot with the alloy. Although he performed the task outdoors, he inserted his head into the pot without a protective mask and therefore inhaled a large amount of fumes. The duration of this soldering procedure was $30 \mathrm{~min}$. He then experienced nausea that resolved itself within 20 min and noticed a sweet taste in

1 First Department of Internal Medicine, Nagoya University School of Medicine, Nagoya, Japan.

2 Department of Hygiene, Nagoya University School of Medicine, Nagoya, Japan.

3 Nagoya City Envirommental Science Research Institute, Nagoya, Japan.

4 Department of Internal Medicine, Japanese Red Cross Nagoya First Hospital, Nagoya, Japan.

Reprint requests to: Dr E Shibata, Department of Hygiene, Nagoya University School of Medicine, 65 Tsurumai, Showa-ku, Nagoya 466, Japan. 
his mouth when he had a cigarette. That night he experienced dyspnea, chills, and fever, and the following day he suffered from progressive dyspnea, fatigue, and cough. On the day of hospital admission ( $3 \mathrm{~d}$ after exposure) he complained of severe fatigue and dyspnea all day and was hospitalized late that evening.

The patient's medical history was notable for a smoking habit consisting of two packs of cigarettes a day for 20 years. Ten years earlier, he had worked as a welder in an automobile factory for one year and had performed silver soldering. However, he had worked wearing a mask with appropriate ventilation at that time. Recently, he had done construction work and assembled machines on his own. The recent soldering with a silver alloy was only his second exposure to silver solder, and he recalled the mild dyspnea associated with his initial exposure.

Physical findings included moist rales heard at the bases of both lungs. He had a temperature of $38.5^{\circ} \mathrm{C}$.

A urinalysis indicated mild proteinuria, and the sediment contained some renal tubule cells. Hematologic studies revealed leukocytosis $\left(26400 \cdot \mu \mathrm{I}^{-1}\right)$. His serum C-reactive protein concentration rose to 30.3 (normal $<0.3) \mathrm{mg} \cdot \mathrm{dl}^{-1}$. The lactate dehydrogenase (LDH) concentration was 1420 (normal 136 to 305 ) IU $\cdot 1^{-1}$, but the other blood chemistry findings were normal. The results of an arterial blood gas analysis of a sample obtained while the patient was breathing room air included a partial pressure of oxygen $\left(\mathrm{PaO}_{2}\right)$ of $51.0 \mathrm{~mm} \mathrm{Hg}(6.8 \mathrm{kPa})$, a partial pressure of carbon dioxide $\left(\mathrm{PaCO}_{2}\right)$ of $30.9 \mathrm{~mm}$ $\mathrm{Hg}(4.1 \mathrm{kPa})$, and a $\mathrm{pH}$ of 7.452 . A chest roentgenogram revealed "ground-glass" shadows in the right lower lung field. Computed tomography (CT) of the chest showed diffuse regions of high density, predominantly in the lower lung fields; these findings were consistent with changes in the pulmonary interstitium.

Initially, our diagnosis was metal fume fever on the basis of his history. The patient was treated conservatively with oxygen and the prophylactic use of cefotiam. However, on the fifth day after exposure, his dyspnea rapidly worsened, and he required more oxygen. A repeat chest CT revealed pulmonary edema. On the seventh postexposure day, a repeat arterial blood gas analysis was performed while the patient was receiving $100 \%$ oxygen via a face mask. The results revealed a $\mathrm{PaO}_{2}$ of $53.6 \mathrm{~mm} \mathrm{Hg}(7.1 \mathrm{kPa})$, a $\mathrm{PaCO}_{2}$ of $37.8 \mathrm{~mm} \mathrm{Hg}$ $(5.0 \mathrm{kPa})$, and a $\mathrm{pH}$ of 7.463. An endotracheal tube was inserted for mechanical ventilation. Methylprednisolone ( $1 \mathrm{~g}$, intravenously) was administered daily for $3 \mathrm{~d}$.

The patient improved steadily and was weaned from the respirator on the fourteenth postexposure day. On day 24 , an analysis of a specimen of arterial blood that was drawn while the patient was breathing room air revealed a $\mathrm{PaO}_{2}$ of $83.3 \mathrm{~mm} \mathrm{Hg}(11.1 \mathrm{kPa}), \mathrm{PaCO}_{2}$ of $44.0 \mathrm{~mm} \mathrm{Hg}(5.8 \mathrm{kPa})$, and a $\mathrm{pH}$ of 7.431 . The laboratory findings for urine and blood were normal. A chest roentgenogram revealed only small reticular shadows remaining in the lower lung fields. The chest CT demonstrated a reduction of the high density areas in the lower lungs. He was discharged on postexposure day 25 after his symptoms resolved well. Three weeks after his discharge, the patient underwent a lung function study. The results included a vital capacity (VC) of 4.041 (104\% of predicted), a forced expiratory volume in $1 \mathrm{~s}\left(\mathrm{FEV}_{1.0}\right)$ of 3.511 ( $84 \%$ of predicted), and a diffusion capacity (DLCO) of $18.0 \mathrm{ml} \cdot \mathrm{min} \cdot \mathrm{mm} \mathrm{Hg}$ (62\% of predicted).

We identified the transient renal impairment experienced by this patient during the course of his illness as consistent with cadmium-induced renal toxicity. The urinary $\beta_{2}$-microglobulin concentration measured by radioimmunoassay was 47220 and 804 (normal, 6.0 to 169) $\mu \mathrm{g} \cdot 1^{-1}$ on postexposure days 7 and 22 , respectively. Although we could not exclude the possibility of druginduced renal damage, the abnormal urinalysis findings on admission suggested that the renal tubular damage was caused by inhaled cadmium before admission. On the other hand, his serum creatinine level and creatinine clearance remained normal throughout the disease course.

\section{Methods}

Sampling. We collected 24-h urine specimens from the 6 th to the 20th hospital day (postexposure days 8 through 22). Unfortunately, the samples from postexposure days 6 and 13 were lost, and only spot samples were obtained on postexposure days 5,7 , and 23 . The samples were stored at $-20^{\circ} \mathrm{C}$ in sterile bottles of polyethylene until analysis. No blood specimens were stored.

Measurement of urinary metal concentrations. Concentrations of urinary metals were determined using flame or flameless atomic absorption spectrometry after wet digestion by nitric acid. The standard addition method was used for the flameless atomic absorption spectrometry. The detection limit was $0.5 \mu \mathrm{g} \cdot 1^{-1}$ for cadmium. The coefficient of variation was within $5 \%$ for all metals $(\mathrm{N}=5)$. For the external quality control, we used standard reference material 1577 a bovine liver supplied by the National Bureau of Standards in the United States.

\section{Results}

The urinary cadmium concentrations were elevated for longer than two weeks after the exposure (table 1). The maximum urinary cadmium concentration among the 24-h urine samples was $24.0 \mu \mathrm{g} \cdot 1^{-1}$ on postexposure day 8 . The maximum urinary cadmium concentration among all of the samples was $86.3 \mu \mathrm{g} \cdot 1^{-1}$ on postexposure day 7 . The cadmium concentration on postexposure day 7 was higher than that on postexposure day 5 . 
Table 1. Urinary cadmium concentrations.

\begin{tabular}{lc}
\hline Day & Cadmium $\left(\left.\mu \mathrm{g} \cdot\right|^{-1}\right)$ \\
\hline 5 & $24.0^{\mathrm{a}}$ \\
7 & $86.3^{\mathrm{a}}$ \\
8 & 24.0 \\
9 & 20.7 \\
10 & 7.4 \\
11 & 9.4 \\
12 & 16.0 \\
14 & 10.9 \\
15 & 16.4 \\
16 & 10.0 \\
17 & 6.1 \\
18 & 3.8 \\
19 & 7.4 \\
20 & 4.8 \\
21 & 5.6 \\
22 & 3.3 \\
23 & $5.5^{\mathrm{a}}$ \\
\hline
\end{tabular}

a The data were examined using spot samples.

Similarly, copper excretions were elevated until postexposure day 17 and slowly returned to normal thereafter. The zinc excretion did not follow such a pattern.

\section{Discussion}

Inhaled cadmium fumes caused chemical pneumonitis in this patient and increased the capillary permeability, leading to severe pulmonary edema. Initially, we misdiagnosed him as a case of metal fume fever. The aggressive disease course and pulmonary infiltrations soon indicated chemical pneumonitis. Moreover, we corroborated his excessive exposure to cadmium fumes by determining the urinary cadmium concentration. Silver soldering also generates small amounts of silver, zinc, and copper fumes (1). However, chemical pneumonitis due to these types of fumes is very rare, albeit they could cause metal fume fever in conjunction with the early course of this patient.

There have been many reports on the urinary cadmium concentration of welders with histories of chronic cadmium exposure or of the general population. The urinary cadmium concentration increases in proportion to the amount of cadmium accumulating in the body (5). Leduc et al (6) found that cadmium was retained in the lung of a welder who was chronically exposed to cadmium fumes, and they continued to detect excessive urinary cadmium excretion for 10 years after his retirement.

On the other hand, although there have been many reports of patients diagnosed with acute cadmium poisoning $(4,7-11)$, most of the reports were based on patients' histories and symptoms. Because information regarding urine and blood cadmium concentrations is limited, the value of these concentrations as predictors of body burden or recent exposure remains unclear. In some cases, urinary cadmium concentrations were normal at the time of diagnosis $(7,8)$. Lucas et al $(9)$ have reported a case of a welder who died of cadmium pneumonitis on postexposure day 5 , and the urinary cadmium concentration of an antemortem specimen was $2000 \mathrm{nmol} \cdot \mathrm{l}^{-1}$ (normal, $\left.<112 \mathrm{nmol} \cdot \mathrm{l}^{-1}\right)$. Blejer et al $(10)$ have reported two cases of acute cadmium fume poisoning with increased cadmium concentrations in the urine on postexposure day 4 in the fatal case $\left(0.5 \mu \mathrm{g} \cdot \mathrm{ml}^{-1}\right)$ and on postexposure day 13 in the nonfatal case $\left(0.05 \mathrm{mg} \cdot 1^{-1}\right)$. These case reports suggest that after excessive cadmium exposure, there may be temporary elevations in urinary cadmium excretion, but it remains unclear how long these elevations persist.

Our data suggest that elevated urinary cadmium excretions may persist for longer than two weeks following exposure, although the period during which one can detect excessive urinary cadmium might vary with the total body burden or the presence of renal damage. Furthermore, the cadmium concentration was higher on postexposure day 7 than on day 5 . We have to interpret these results with caution because we did not correct the urine dilution. However, the finding is consistent with the findings of Blejer et al (10), who found a normal urinary cadmium concentration during the first day but an elevated one on postexposure day 13. Inhaled cadmium is absorbed into the lung and transported by the blood to the liver and kidneys, where most of the cadmium is stored $(2,5)$. The cadmium urinary excretion increases when the cadmium cannot be further retained in the organs after its concentration becomes saturated, or when cadmium-induced renal damage develops, as in the case of the patient under study (5). This phenomenon might explain why the urinary cadmium concentration peaks several days after exposure.

We confirmed a transient increased urinary cadmium excretion after excessive exposure to this metal. Therefore, the measurement of urinary cadmium concentrations in such patients is an effective method for verifying recent cadmium poisoning.

\section{References}

1. Hara N, Homma K, Koshi S. Metallic fume generated in the welding using silver solder. Ind Health 1968;6:134-9.

2. Lee JS, White KL. A review of the health effects of cadmium. Am J Ind Med 1980;1:307-17.

3. Sferlazza SJ, Beckett WS. The respiratory health of welders. Am Rev Respir Dis 1991;143:1134 48.

4. Barnhart S, Rosenstock L. Cadmium chemical pneumonitis. Chest 1984;86:789-91.

5. World Health Organization (WHO). Cadmium. Geneva: WHO, 1992. Environmental health criteria, no 134.

6. Leduc D, de Francquen P, Jacobovitz D, Vandeweyer R, Lauwerys $R$, De Vuyst $P$. Association of cadmium exposure with rapidly progressive emphysema in a smoker. Thorax 1993; 48:570-1.

7. Beton DC, Andrews GS, Davies HJ, Howells L, Smith GF. Acute cadmium fume poisoning: five cases with one death from renal necrosis. Br J Ind Med 1966;23:292-301. 
8. Yates DH, Goldman KP. Acute cadmium poisoning in a foreman plater welder. Br J Ind Med 1990;47:429_31.

9. Lucas PA, Jariwalla AG, Jones JH, Gough J, Vale PT, Fatal cadmium fume inhalation [letter]. Lancet 1980;I:205.

10. Blejer HP, Caplan PE, Alcocer AE. Acute cadmium fume poisoning in welders - a fatal and a nonfatal case in Califor- nia. Calif Med 1966;105:290-6.

11. Seidal K, Jörgensen N, Elinder C-G, Sjögren B, Vahter M. Fatal cadmium-induced pneumonitis [case report]. Scand J Work Environ Health 1993;19:429-31.

Received for publication: 7 August 1995 